\title{
Extraction Procedure, Characteristics, and Feasibility of Caulerpa microphysa (Chlorophyta) Polysaccharide Extract as a Cosmetic Ingredient
}

\author{
Meng-Chou Lee ${ }^{1,2,3} \mathbb{1}$, Han-Yang Yeh ${ }^{1}\left(\mathbb{D}\right.$ and Wen-Ling Shih ${ }^{4, *}$ \\ 1 Department of Aquaculture, National Taiwan Ocean University, Keelung City 20224, Taiwan; \\ mengchoulee@email.ntou.edu.tw (M.-C.L.); $20833001 @$ mail.ntou.edu.tw (H.-Y.Y.) \\ 2 Center of Excellence for Ocean Engineering, National Taiwan Ocean University, Keelung City 20224, Taiwan \\ 3 Center of Excellence for the Oceans, National Taiwan Ocean University, Keelung City 20224, Taiwan \\ 4 Department of Biological Science and Technology, National Pingtung University of Science and Technology, \\ 1, Shuefu Rd., Pingtung 91201, Taiwan \\ * Correspondence: wlshih@mail.npust.edu.tw; Tel.: +886-8-770-3202 (ext. 5192); Fax: +886-8-774-0550
}

Citation: Lee, M.-C.; Yeh, H.-Y.; Shih, W.-L. Extraction Procedure, Characteristics, and Feasibility of Caulerpa microphysa (Chlorophyta) Polysaccharide Extract as a Cosmetic Ingredient. Mar. Drugs 2021, 19, 524. https://doi.org/10.3390/md19090524

Academic Editor:

William Lindsey White

Received: 10 August 2021

Accepted: 15 September 2021

Published: 18 September 2021

Publisher's Note: MDPI stays neutral with regard to jurisdictional claims in published maps and institutional affiliations.

Copyright: (c) 2021 by the authors. Licensee MDPI, Basel, Switzerland. This article is an open access article distributed under the terms and conditions of the Creative Commons Attribution (CC BY) license (https:// creativecommons.org/licenses/by/ $4.0 /)$.

\begin{abstract}
The green alga Caulerpa microphysa, which is native to Taiwan, has a relatively high economic value and a well-developed culture technique, and is used mainly as a foodstuff. Its extract has been shown to exhibit antitumor properties, but the polysaccharide content of the extract and its antiinflammatory and wound-healing effects and moisture-absorption and -retention capacity remain unknown. Hence, the objective of this study was to evaluate the potential of the polysaccharides in C. microphysa extract (CME) for use in cosmetics. The overall polysaccharide yield from the CME was $73.93 \% w / w$, with four molecular weight fractions. The polysaccharides comprised $59.36 \mathrm{~mol} \%$ mannose, $27.16 \mathrm{~mol} \%$ glucose, and $13.48 \mathrm{~mol} \%$ galactose. In addition, the CME exhibited strong antiallergic, wound-healing, transdermal-delivery, and moisture-absorption and -retention effects. In conclusion, the results suggested that CME potentially has anti-inflammatory and wound-healing effects and a good moisture capacity, which can be used in cosmetic applications.
\end{abstract}

Keywords: Caulerpa; polysaccharides; anti-inflammation; moisture capacity; wound healing

\section{Introduction}

The commercial production of marine algae has been rapidly increasing over recent decades, whether by harvesting from natural resources or by cultivation. The application of algae is regarded as environmentally friendly, healthy, and sustainable for human beings [1]. Algae contain many compounds that can be used as foodstuffs, cosmetics, medicines, and pharmaceuticals, and they can also be used in aquaculture and agriculture [1]. This is because algae contain biochemical compounds such as pigments, lipids, cellulose, minerals, and polysaccharides, which have anticarcinogenic, anti-pigmentation, anti-dermatitis, emollient, humectant, antioxidant, anti-inflammatory, whitening, and anti-aging properties [2]. Among these compounds, a family of polysaccharides has been regarded as the most potentially effective for anti-inflammatory and wound-healing treatments [3]. Previous studies have revealed that their biological activity may be affected by their molecular weight, monosaccharide composition, polysaccharide dose concentration, and antioxidant content [4-6].

Notably, the extraction process is crucial for obtaining polysaccharides [7]. In general, hot water is considered the optimal solvent for the extraction of polysaccharides, and is often combined with autoclaving, microwaving, and ultrasonication [4,7]. These methods and instrumentation may not only affect the final extracted yield but also play a role in the overall economic cost [8,9]. Additionally, the crushing or milling, drying, and conservation process may also influence the extraction efficiency. In spite of the importance of these 
aspects, however, little information has been reported regarding the optimal extraction strategy for algae $[4,7]$.

Furthermore, the structure of polysaccharides is complicated, which usually consists of various monosaccharides and esters. Thus, clarifying the structures and compositions of polysaccharides is crucial to comprehend the characteristics and potential functions of the objective sample [10]. In current, a series of approaches to methods for analyzing structures and compositions of polysaccharides have been reported. Acidic hydrolysis which involves acids such as $\mathrm{HCl}$ and $\mathrm{H}_{2} \mathrm{SO}_{4}$ is generally used to release the monosaccharides [10,11]. Liquid chromatography (LC), nuclear magnetic resonance (NMR), gas chromatography (GC), and mass spectrometry (MS) are usually used to analyze monosaccharides [10,12,13]. Notably, 2,3-naphthalene-diamine (NADA) can be used for the derivatization of aldoses and $\alpha$-ketoacid-type to increase the efficiency for analyses [12]. Fluorescent monosaccharide labeling for NMR can increase the accuracy in identifying the monosaccharides and structure [10]. Those methods above are useful to optimize the qualitative and quantitative analysis of polysaccharides.

Inflammatory responses, also known as allergies, are induced by the degranulation of mast cells, which is an abnormal symptom associated with the overreaction of the immune system [13]. This response is debilitating, causing asthma, rhinitis, dermatitis, and other clinical allergy symptoms [14]. Wound healing involves the regeneration and replacement of connective tissue, and this process is frequently accompanied by inflammatory or other potentially injurious reactions. More specifically, wound healing is defined as the migration and proliferation of dermal and epidermal cells to fill or cover the wound, which is a dynamic process of tissue remodeling [15]. Notably, some people exhibit adverse reactions or need much longer recovery periods as a result of inflammatory inhibition of wound healing because of disease or a weakened immune system. Fortunately, previous studies have demonstrated the curative effects of some anti-inflammatory and woundhealing-accelerating substances extracted from plants, especially the polysaccharides found in marine algae [2,16]. Because of the similar chemical and biological properties of algal polysaccharides and mammalian glycosaminoglycan, the former are considered to contribute to immunoregulation in mammals [17]. However, although algae share similar polysaccharide structures, compound functions are determined by additional features such as chemical composition, molecular weight, and position on the polymer backbone. Thus, each algal species should be evaluated individually, because of their high degree of complexity and differing bioactive compounds [6].

The green alga Caulerpa microphysa (Weber Bosse) Feldmann 1955, also known as sea grape, is native to the intertidal zones in Taiwan, Japan, China, and the Philippines. It has a high economic value and a well-developed culture technique [18]. This alga consists mainly of carbohydrates (up to $70 \% w / w$, data not shown), and is mainly used as a foodstuff, as feed, as aquarium algae, and for water-quality control, and it is popular as a traditional food. Building on its well-established culture technique and stable biomass supply, previous research has confirmed its antitumor properties using polypeptides extracted from it [19]. Extracts of other algal species have also been found to have positive pharmacological effects, such as the anticoagulant and antioxidant effects of polysaccharides extracted from C. cupressoides, the antioxidant effects of polysaccharides extracted from C. prolifera [20], the antiviral effects of the crude extract of C. taxifolia [21], and the antiproliferative effects of the crude extract of $C$. racemosa [22]. Although multiple functional properties have been demonstrated, there have been no reports on the anti-inflammatory and wound-healing properties of algae, particularly with regard to C. microphysa.

To further develop the pharmacological applications of C. microphysa, the objective of this study was to first develop the optimal polysaccharide extraction conditions for cultured C. microphysa, and then to identify and analyze the polysaccharides. Next, we hypothesized that the polysaccharide-rich extract of $C$. microphysa (CME) contains potentially useful bioactive compounds, and investigated the anti-inflammatory, wound-healing, and 
moisture-retention effects of various doses of CME. We expected to find that these polysaccharides could provide natural, healthy, safe, and effective raw materials for cosmetics.

\section{Results and Discussion}

2.1. Effects of Drying, Milling, and Extraction Procedures, and the Freeze-Drying Preservation of the Polysaccharide Yield

It is crucial to optimize extraction procedures based on the objectives of production [7]. In general, polysaccharide yield is positively correlated with both temperature and reaction period, but increasing these factors increases costs in terms of time and energy. However, the current situation may be changing as a result of the microwave-ultrasound extraction method, which has been shown to increase extraction efficiency for the microalga Scenedesmus obliquus, using lipid extraction, and for the red alga Porphyra haitanensis, using water-based extraction, but its efficiency with regard to green macroalgae remains unknown $[4,7,23]$. In addition, identifying the best drying and cell-disruption methods is crucial for optimizing the extraction process and decreasing the cost in terms of energy and time to achieve large-scale productivity $[23,24]$.

The effects of the drying, milling, and extraction procedure used in this study on the polysaccharide yield are presented in Figure 1. Three factors significantly affected polysaccharide yield. The autoclave method was significantly more efficient than the microwave-ultrasound method. Both drying and milling improved extraction efficiency when using the microwave-ultrasound method, but only drying had any effect when using the autoclave method. Our result was different from those obtained for Scenedesmus obliquus and Porphyra haitanensis in previous studies, since we found that the extraction efficiency of the microwave-ultrasound method was lower than that of the autoclave method. This may be due to the use of different pretreatments and solvents [4,7]. Ansari et al., (2015) used lipid as a solvent to extract microalgae $S$. obliquus after cellulose was hydrolyzed by using $\mathrm{H}_{2} \mathrm{SO}_{4}$, and found that compared with autoclave, ultrasonication can obtain more reduced sugar [7]. The result may be due to the hydrolyzed cell wall, and the better thermal conductivity of lipid than water. Thus, lipid solvent can penetrate the sample and heat production to extract reduced sugar under ultrasonication adequately [8]. Whereas C. microphysa possessed an intact cell wall, which meant that the water solvent was hard to contact the algae sufficiently. Simultaneously, the heat production could not sufficiently destroy the inner cell wall tissue and release the polysaccharides under microwave-ultrasound extraction method. By comparison, the autoclave method was more effective in destroying cell walls than microwave-ultrasound extraction method by providing high thermal and pressure directly and then releasing polysaccharides from cells in this study.

Drying and milling improved the polysaccharide yield when followed by the microwaveultrasound procedure, which suggests that the cell disruption resulting from this step aided the reaction of the solvent and heat transfer. However, drying resulted in a lower polysaccharide yield than just milling fresh samples when the autoclave method was used. It is thus likely that a loss of polysaccharides occurred during the drying process. In consideration of these findings, we prepared the CME from milled fresh algae, using the autoclave method, for use in further experiments with respect to freeze-drying preservation of the extract, the polysaccharide and polyphenol yield from samples kept with both types of cover was lower than that from the control samples. The polysaccharide recovery rate when using the aluminum foil and parafilm was $76.38 \pm 7.06 \%$ and $53.64 \pm 4.07 \%$ of the yield from the control samples, respectively, and the polyphenol recovery rate was $88.70 \pm 2.07 \%$ and $86.88 \pm 2.13 \%$, respectively. In addition, after the freeze-drying and restoration processes, the $\mathrm{pH}$ of the samples covered with aluminum foil was $7.38 \pm 0.61$ and of those covered with parafilm was $7.66 \pm 0.15$, while that of the control was $5.81 \pm 0.1$ (Figure 2). Due to the parafilm cover having better resiliency than aluminum foil, thus we could make smaller holes by pin to avoid dried powder spraying during vacuum relief. These results illustrate that using the best freeze-drying procedure and material to cover the extract is important for preserving the polysaccharides. 


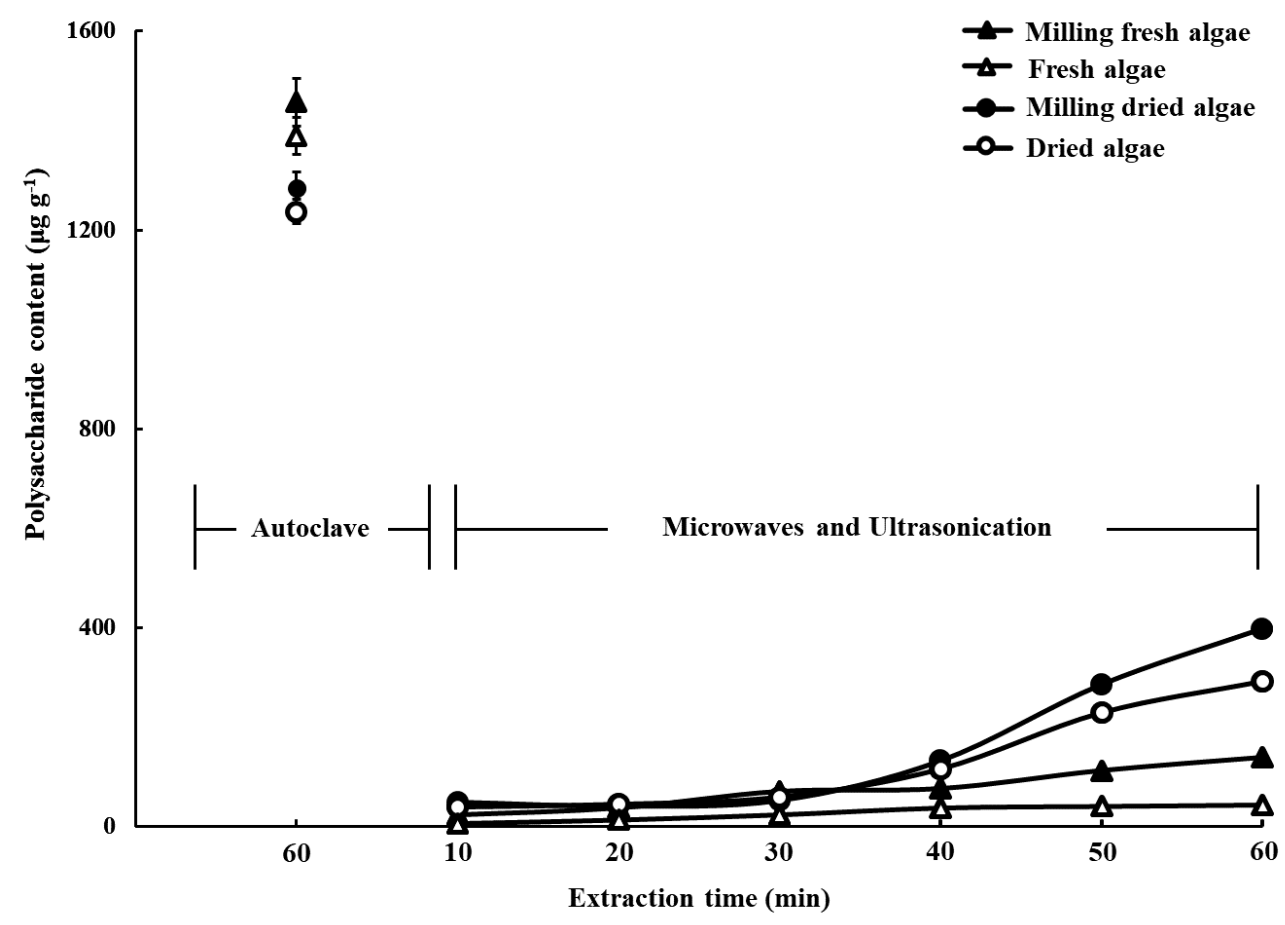

Figure 1. Effect of different pretreatments (none, milling, oven-drying, and both milling and ovendrying) and extraction procedures (autoclave and microwave-ultrasound) on the polysaccharide yield of water-based extraction of Caulerpa microphysa. Bars indicate SD, $n=3$ (One-Way ANOVA and Scheffe's a posteriori test).

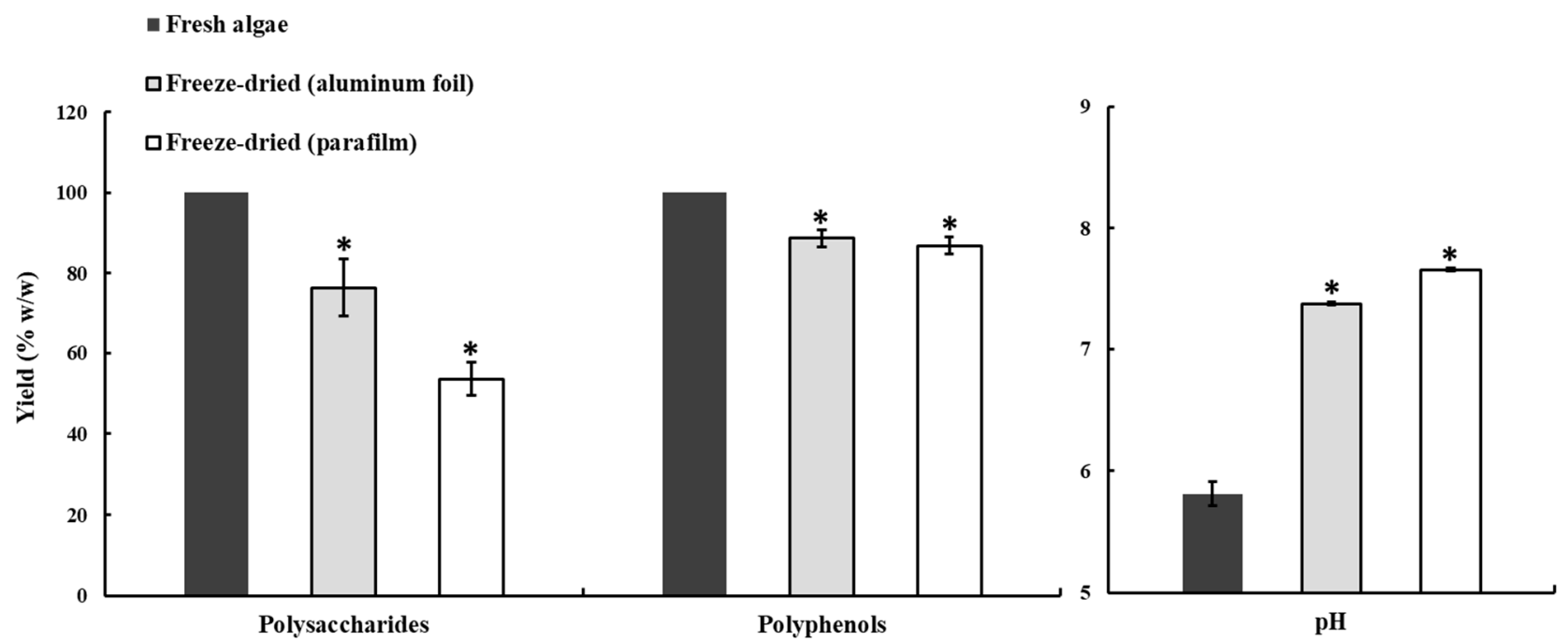

Figure 2. Effect of different freeze-drying covers (aluminum foil and parafilm) on the polysaccharide and polyphenol yield and the substrate $\mathrm{pH}$. Bars indicate $\mathrm{SD}, n=3,{ }^{*}$ indicates a significant difference $(p<0.05)$ compared to control (Student's $t$-test).

\subsection{Monosaccharide, Bioactive Ingredient, and Molecular Composition of CME}

Previous studies have shown that biochemical composition, molecular weight, and chemical structure can affect biological activity [25]. Therefore, a deeper investigation of biochemical compounds is imperative. In this study, the in-depth analysis of the CME showed that it provided a total polysaccharide yield of $1457.17 \pm 48.25 \mathrm{\mu g} \mathrm{g}^{-1}$, comprising $73.4 \% w / w$ of the biomass weight. These saccharides mainly comprised mannose (59.36 $\mathrm{mol} \%)$, glucose $(27.16 \mathrm{~mol} \%)$, and galactose (13.48 mol\%) (Table 1). Additionally, the 
extract provided a polyphenol yield of $16.62 \pm 5.39 \mathrm{\mu g} \mathrm{g}^{-1}$ (Table 2). The molecular weight of the CME was determined via gel filtration chromatography using a refractive index detector system, which revealed four fractions (B1-B4) in the CME. Based on calibration with molecular-weight markers, the apparent molecular weight of B1 was $50-100 \mathrm{kDa}$, while that of the B2 fraction was similar to that of glucose, with an approximate molecular weight of $180 \mathrm{Da}$. The molecular weights of the B3 and B4 fractions were less than that of glucose and beyond the range of the molecular-weight markers (Figure 3).

Table 1. Polysaccharide composition of Caulerpa microphysa polysaccharide-rich extract (CME) analyzed using a nuclear magnetic resonance spectrometer.

\begin{tabular}{cccc}
\hline \multirow{2}{*}{ Total Saccharides $\%(w / w)$} & \multicolumn{3}{c}{ Monosaccharide Composition $\mathbf{m o l} \%$} \\
\cline { 2 - 4 } & Mannose & Glucose & Galactose \\
\hline 73.4 & 59.36 & 27.16 & 13.48 \\
\hline
\end{tabular}

w/w: Monosaccharide weight as a percentage of total saccharide weight.

Table 2. The polysaccharide and polyphenol yield of Caulerpa microphysa polysaccharide-rich extract (CME).

\begin{tabular}{cc}
\hline $\begin{array}{c}\text { Polysaccharides } \\
\left(\mathbf{m g ~ g}^{-\mathbf{1}}\right)\end{array}$ & $\begin{array}{c}\text { Polyphenols } \\
\left.\mathbf{( m g ~ g}^{-\mathbf{1}}\right)\end{array}$ \\
\hline $1457.17 \pm 48.25$ & $16.62 \pm 5.39$ \\
\hline
\end{tabular}
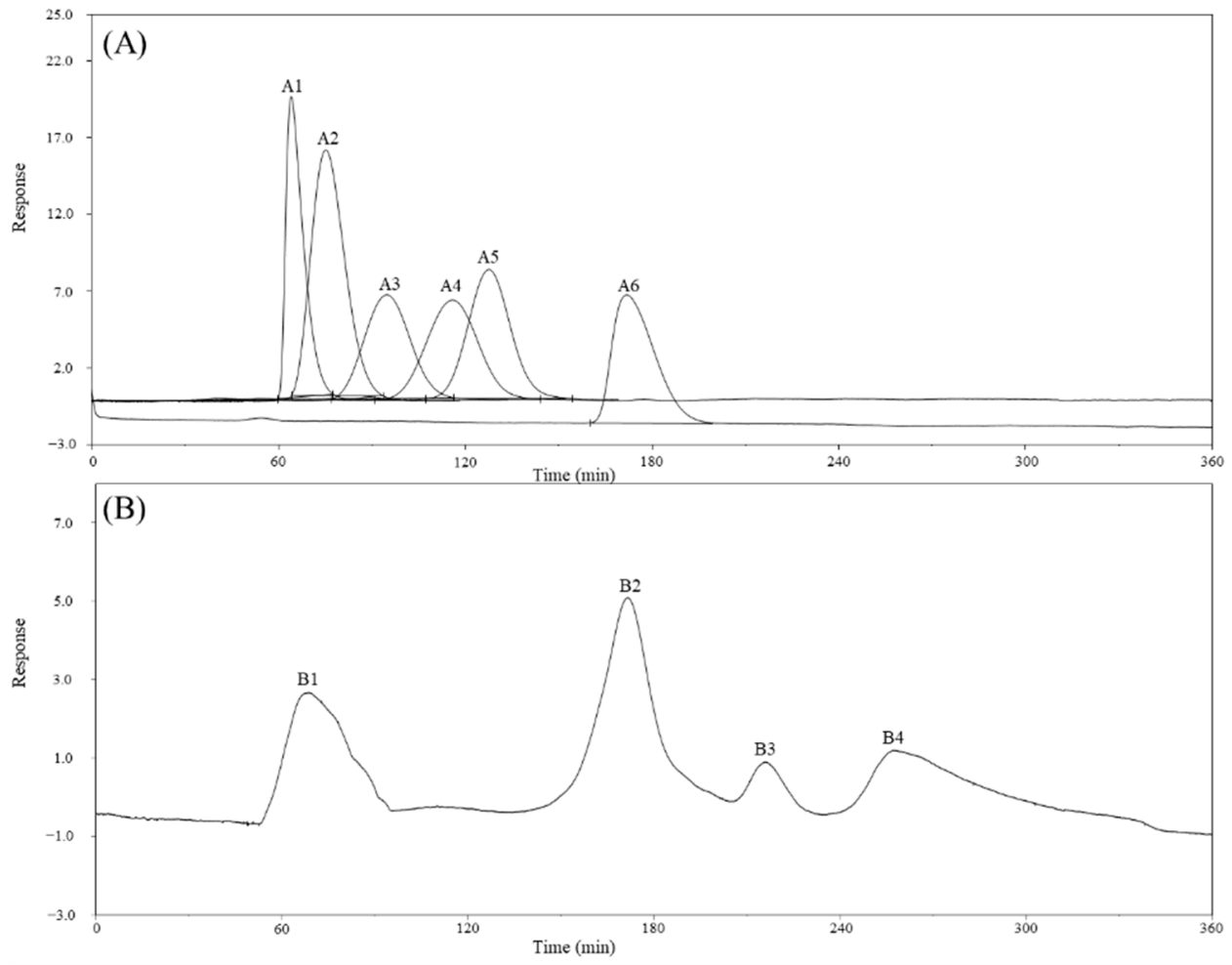

Figure 3. Molecular-weight distribution of (A) molecular-weight markers and (B) Caulerpa microphysa polysaccharide-rich extract (CME). Elution profile of standard pullulans showed A1-A5 are the curves for molecular-weight markers with weights of 100,50, 20, 10, $5 \mathrm{kDa}$, respectively, and A6 indicates the curve for a glucose marker with a weight of $180 \mathrm{Da}$. B1-B4 are the four spectra obtained for CME using gel filtration chromatography with a Sephacryl S-200 High Resolution HiPrep 16/60 column as an eluent at a flow rate of $0.6 \mathrm{~mL} \mathrm{~min}^{-1}$ using a degas pump. 
Comparing our findings with previous research, the total polysaccharide yield with respect to biomass in this study was higher than that of most other water and organic extracts, such as Nannochloropsis oculata at 19\% w/w [6]; Ulva lactuca at 26.01-28.29\% w/w [5]; Parachlorella spp. at $73.8 \% w / w$ [26]; Chondrus verrucosus at $46.2-65.9 \% w / w$ [27]; and Nostoc commune at $82.2-84.6 \% w / w$ [28]. The results of this study suggest the feasibility of using C. microphysa as a cash crop to produce polysaccharides. Furthermore, the monosaccharide composition of the extract obtained in this study was different from that reported previously for species in the Caulerpa genus. For example, C. brachypus consists mainly of rhamnose, xylose, and glucose [11]; C. racemose consists of glucose $(56.8 \mathrm{~mol} \%)$ and galactose (31.8 mol\%) [29]; and C. cupressoides consists mainly of galactose, mannose, and xylose [2]. Although all of these are in the same genus, they differ in their monosaccharide compositions. We also observed that the analysis systems used on the above Caulerpa genus are completely different, but all of them showed the monosaccharide compositions efficiently, e.g., the monosaccharides of $C$. brachypus hydrolyzed using $\mathrm{H}_{2} \mathrm{SO}_{4}$ were analyzed by GLC [11]; the monosaccharides of $C$. racemose hydrolyzed using $\mathrm{HCl}$ were analyzed by GC [29]; the monosaccharides of $C$. cupressoides hydrolyzed using $\mathrm{HCl}$ were analyzed by HPLC-RI [20] (Table 3). Notably, the monosaccharides in our study were obtained using $\mathrm{HCl}$ hydrolysis, and analyzed by both ${ }^{1} \mathrm{H}$ NMR and HPLC-UV after Sugar-NAIM derivatization, and these two instruments showed the same monosaccharides composition (Figures 4 and 5). The mentions above illustrated the diversity of the techniques which are beneficial to develop the studies in the carbohydrates field.

Table 3. Comparison of analysis systems and monosaccharides compositions in the Caulerpa genus.

\begin{tabular}{|c|c|c|c|}
\hline Species & Analysis Systems & Monosaccharides Composition & References \\
\hline Caulerpa microphysa & $\begin{array}{c}\mathrm{HCl} \text { hydrolysis, } \\
\text { Sugar-NAIM }{ }^{*} \text { derivatization, } \\
{ }^{1} \mathrm{H} \mathrm{NMR}^{*} \text { and } \mathrm{HPLC}^{*}-\mathrm{UV} \text { analysis }\end{array}$ & $\begin{array}{c}\text { Total sugar }(w / w): 73.4 \% \\
\text { Mannose } 59.36 \% \text {, Glucose } 27.16 \% \text {, } \\
\text { Galactose } 13.48 \%\end{array}$ & This study \\
\hline C. brachypus & $\begin{array}{l}\mathrm{H}_{2} \mathrm{SO}_{4} \text { hydrolysis, } \\
\mathrm{GLC}^{*} \text { analysis }\end{array}$ & Rhamnose, Xylose, Glucose & $\begin{array}{c}\text { Lee et al., } 2004 \\
{[11]}\end{array}$ \\
\hline C. racemosa & $\begin{array}{l}\mathrm{HCl} \text { hydrolysis, } \\
\mathrm{GC}^{*} \text { analysis }\end{array}$ & $\begin{array}{c}\text { Total sugar }(w / w): 36-53.7 \% \\
\text { Uronic acid }(w / w): 3.9-7.9 \% \\
\text { Neutral sugar (Glucose } 56.8 \% \text {, } \\
\text { Galactose } 31.8 \% \text {, Mannose } 11.4 \% \text { ) }\end{array}$ & $\begin{array}{l}\text { Ji et al., } 2008 \\
\text { [29] }\end{array}$ \\
\hline C. cupressoides & $\begin{array}{l}\mathrm{HCl} \text { hydrolysis, } \\
\text { HPLC-RI* analysis }\end{array}$ & $\begin{array}{l}\text { Total sugar }(w / w): 52.38-59.60 \% \\
\text { Galactose, Glucose, Mannose, } \\
\text { Xylose, Rhamnose, Fucose }\end{array}$ & $\begin{array}{c}\text { Costa et al., } 2012 \\
\text { [20] }\end{array}$ \\
\hline
\end{tabular}

*NAIM: Naphthimidazole; *NMR: Nuclear Magnetic Resonance spectroscopy; HPLC: High-performance liquid chromatography; ${ }^{*}$ GLC: Gas-liquid chromatography; *GC: Gas Chromatography; *RI: Refractive Index.

Previous studies have been summarized reported that the glycosidic bonds of Caulerpa genus including 4-Linked xylose, 6-linked galactose, 4-linked mannose, 6-linked $\alpha$-Dmannopyranose, and 4-linked and 2-linked $\alpha$-D-mannopyranose [30]. However, due to the information on the structure of the polysaccharides are not enough, the critical mechanism and function are not clarified [31]. Our result found the most monosaccharide in C. microphysa was mannose and followed were glucose and galatose. Although the monosaccharide composition and has been determined, its detailed glycosidic bonds were not clear. Hence, our further study will focus on investigating the potential glycosidic bond's effect on the bioactivity of $C$. microphysa.

\subsection{In Vitro $\beta$-Hexosaminidase Secretion Inhibition Assay}

Allergies are a common health problem, affecting approximately $20 \%$ of the global population [32,33]. Antiallergic compounds usually act on mast cells, which are known to play a major role in the immediate type of allergic reaction. The signaling pathway involves binding of the IgE receptor to antigens, followed by the induction of degranulation in mast cells, which results in the release of chemical mediators including histamine, leukotrienes, 
and prostaglandins [34]. To evaluate the degranulation process resulting from an allergic reaction, RHB-2H3 cells, which are mucosal mast cells, can be used [35]. Moreover, $\beta$-hexosaminidase functions as a critical inflammatory mediator and is released along with histamine upon mast cell degranulation [36]. Thus, analysis of $\beta$-hexosaminidase secretion is widely used to evaluate the level of mast cell degranulation.

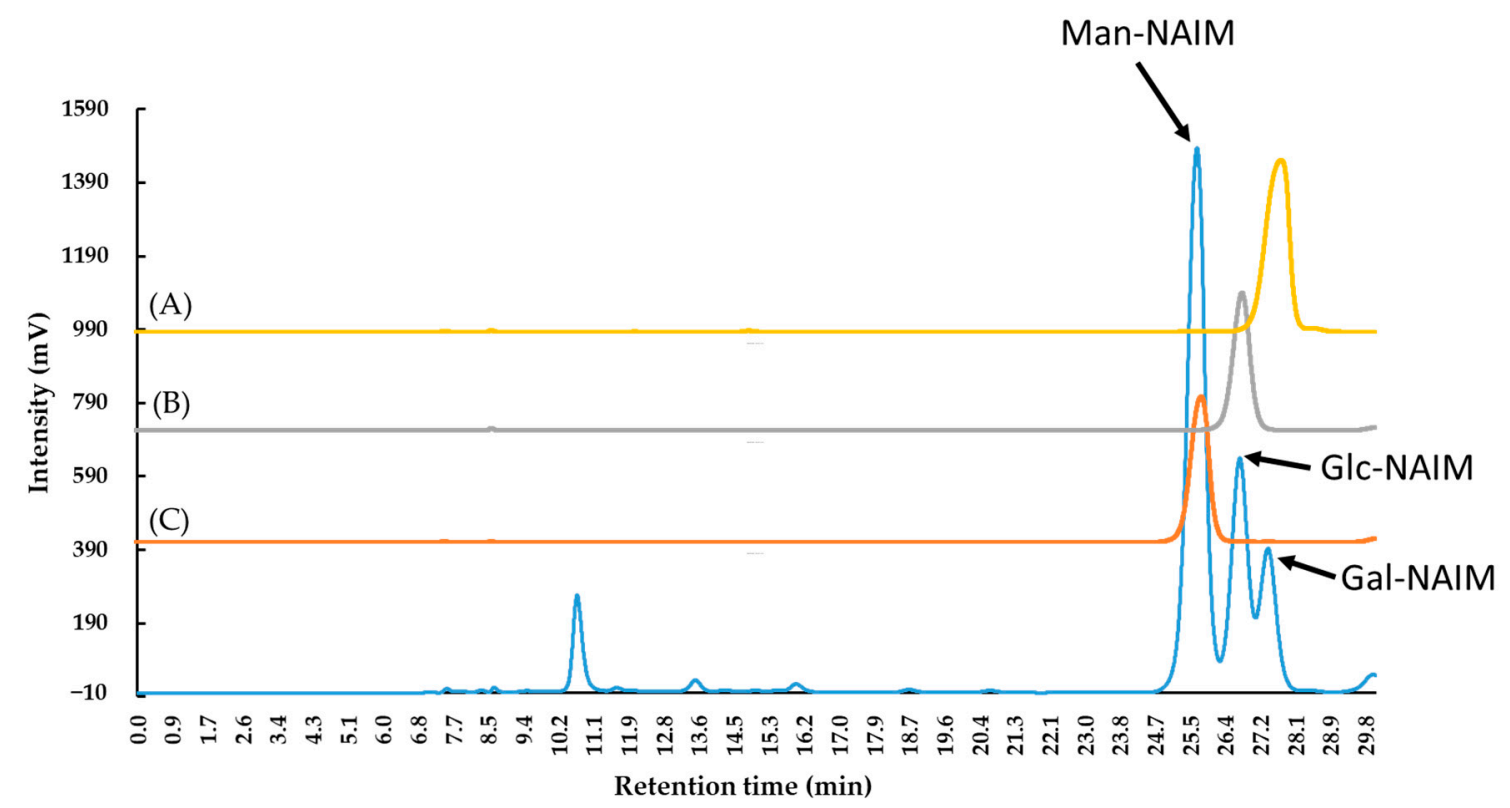

Figure 4. The HPLC-UV spectra of (A) Galactose naphthimidazole (Gal-NAIM) derivative, (B) Glucose naphthimidzaole (Glc-NAIM) derivative, (C) Mannose naphthimidazole (Man-NAIM) derivative, and (D) Caulerpa microphysa polysacchariderich extract (CME) obtained by gel filtration chromatography with a Biosil ODS-W $250 \times 4.6 \mathrm{~mm} 5 \mu$ (C18) column as an eluent at a flow rate of 0.4-1 $\mathrm{mL} \mathrm{min}^{-1}$ using a gradient pump (Chromaster 5160, HITACHI, Tokyo, Japan).

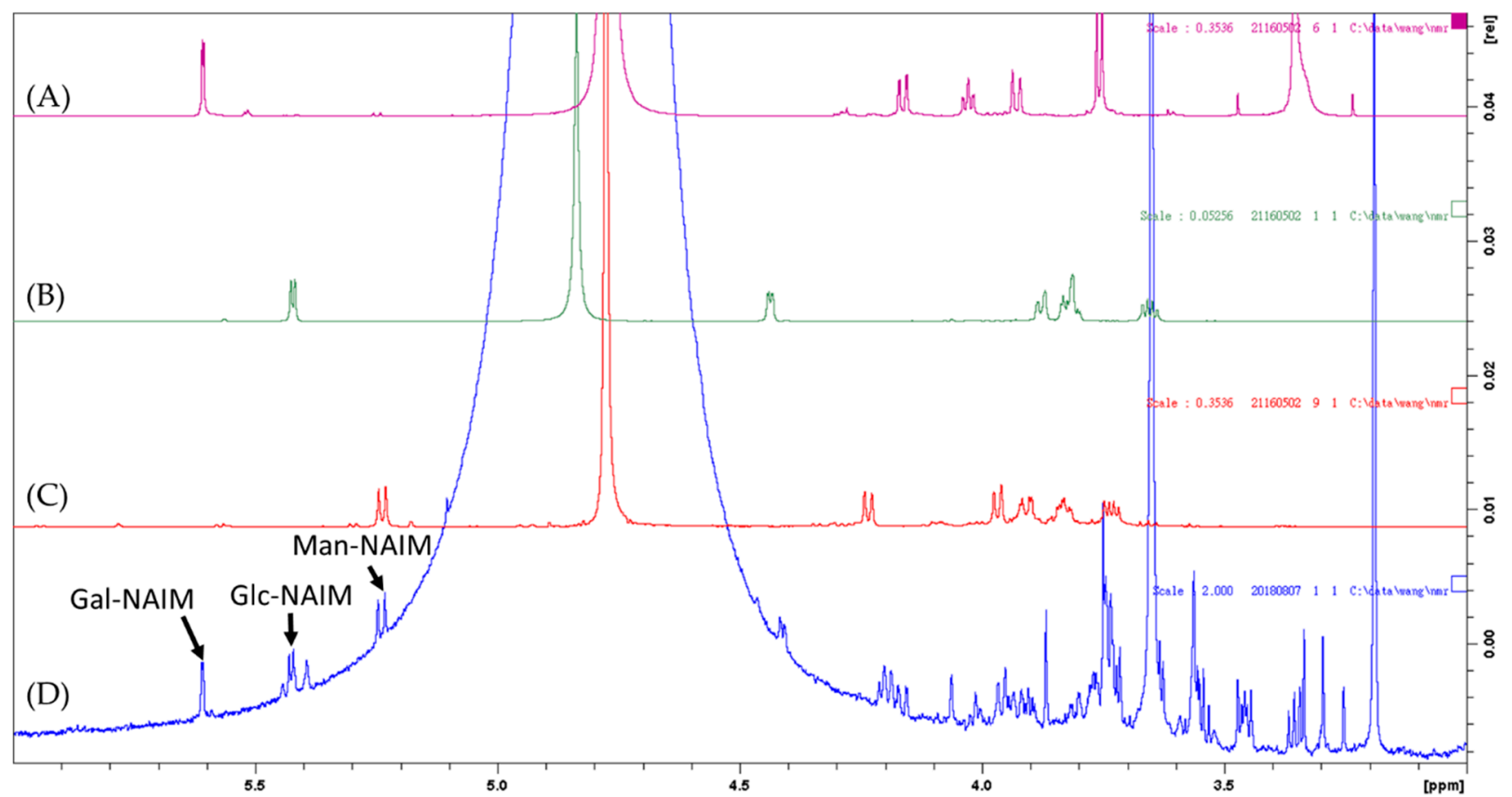

Figure 5. ${ }^{1} \mathrm{H}$ NMR spectra of (A) Galactose naphthimidazole (Gal-NAIM) derivative, (B) Glucose naphthimidzaole (GlcNAIM) derivative, (C) Mannose naphthimidazole (Man-NAIM) derivative, and (D) Caulerpa microphysa polysaccharide-rich extract (CME). 
As shown in Figure 6, antigen-mediated signaling causes a critical increase in the secretion of $\beta$-hexosaminidase. However, CME showed a superior concentration-dependent inhibitory. When $0.25 \%$ of CME were added, the $\beta$-hexosaminidase inhibition rates were more than $50 \%$. When dose of CME more than $0.5 \%, \beta$-hexosaminidase release was almost suppressed completely. Previous in vitro studies reported that the hot water extract of Ecklonia cava and Chrymenia wrightii have more than 50\% degranulation inhibit at a dose of $100 \mu \mathrm{g} \mathrm{mL}^{-1}$, in addition, MeOH extract of Petalonia binghamiae, Scytosiphone lomentaria, Undaria pinnatifida, Porphyra dentata, Codium fragile, and Ulva japonica have more than $50 \%$ degranulation inhibit at a dose of $200 \mu \mathrm{g} \mathrm{mL} \mathrm{L}^{-1}$, illustrate that extract solvent significantly effect on degranulation inhibit [14]. Maruyamam et al., (2005) use in vivo study to show that mekabu fucoidan at a dose of $50 \mu \mathrm{g} \mathrm{mL}^{-1}$ significantly decreased the type 2 T-helper cytokines, IL-4, IL-5, and IL-13 level, which are the chemical mediators to induce degranulation [37]. Overall, our results suggest that effective degranulation inhibitory activity occurs. Compared to CICA extract, which possesses well-known antiallergic activity and is widely used in commercially available products, the antiallergic potential of CME was better at the same concentration.

$\sqsubset \beta$-hexosaminidase secretion

$\rightarrow-$ cell survival

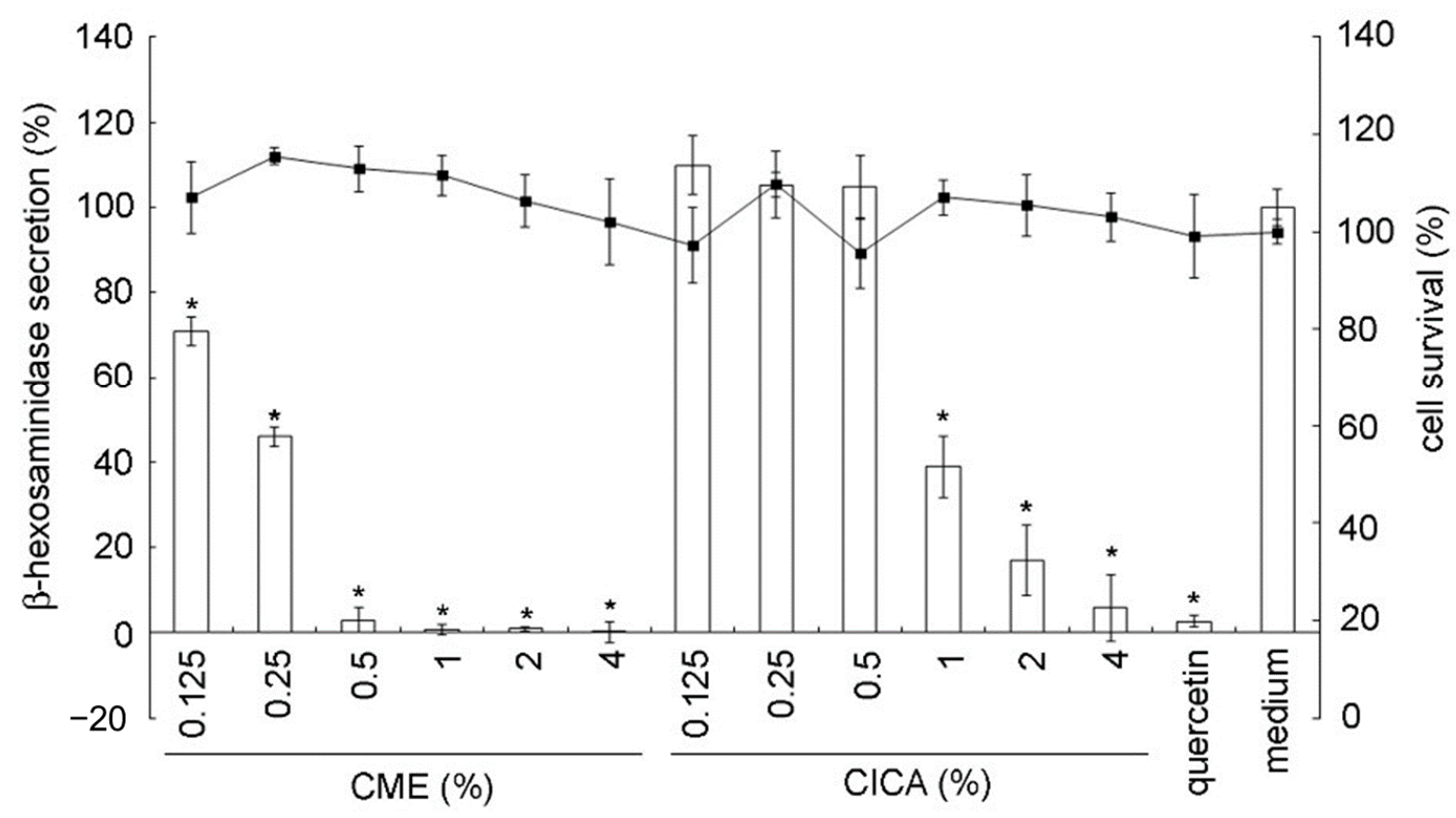

Figure 6. Antiallergic activity of Caulerpa microphysa polysaccharide-rich extract (CME) in RBL-2H3 cells. Bars indicate SD, $n=3 *$ indicates a significant difference $(p<0.05)$ compared to the medium control (Student's $t$-test). CICA: Centella asiatica.

\subsection{In Vitro Wound-Healing Activity Assay}

Healthy, intact, wound-free skin can prevent dehydration, microorganisms and irritants as an important protective way of individual. The in vivo wound healing process is tightly controlled by multiple growth factors released at the wound site, such as Plateletderived growth factor (PDGF), Transforming Growth Factor (TGF), and Epidermal growth factor (EGF). Some natural products have been used extensively in wound care with excellent effects [38] To determine the wound re-epithelialization potential of CME, an artificial and uniform cellular scar was created. TGF- $\beta$, a growth factor, stimulates matrix protein production and induces faster healing, and was therefore included as a positive control [39].

The cellular wound healing after $8 \mathrm{~h}$ of treatment is illustrated in Figure 7A. Compared to the untreated medium control, treatment of 3T3-L1 cells with $0.5 \% \mathrm{CME}$ for $8 \mathrm{~h}$ significantly improved the wound-healing response: wound repair following the $0.5 \%$ 
and 1\% CME treatments increased by approximately 25 and 39\%, respectively (Figure 7B). CICA exhibited significant wound-healing activity at a $1 \%$ concentration. Previous study report that aqueous extract of Spirulina platensis can significantly induce cell migration of HDF cells, which is better than methanolic, ethanolic and allantoin extract [15]. The similar result also observes to methanolic extract of Moringa oleifera inhibit wound healing [40].

(A)
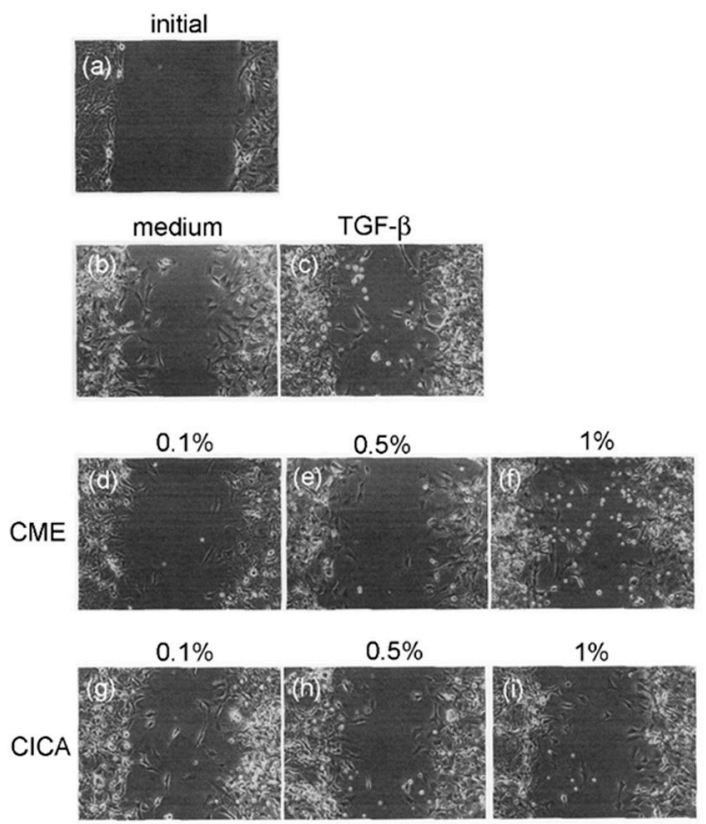

(B)

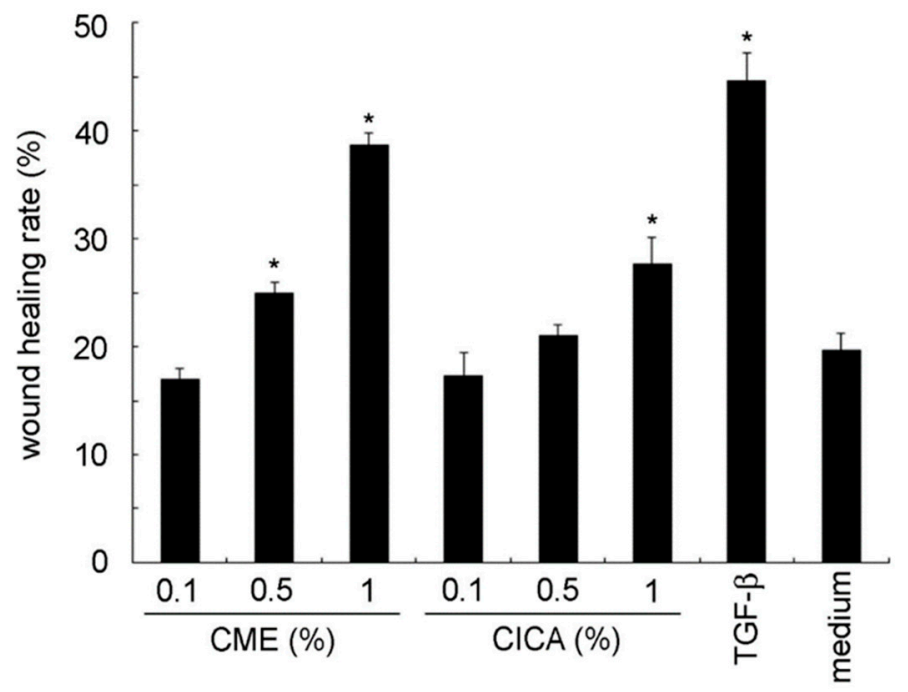

Figure 7. Effects of Caulerpa microphysa polysaccharide-rich extract (CME) on wound healing. (A) Microscope imaging to evaluate wound healing using confluent 3T3-L1 fibroblasts. Representative images showing the initial scratch (wound) at $\mathrm{t}=0(\mathrm{a}), 8 \mathrm{~h}$ after CME treatment $(\mathrm{d}-\mathrm{f})$ and CICA treatment $(\mathrm{g}-\mathrm{i})$ with indicated concentration. Cell migration into the wound area was observed. A single representative area is shown $8 \mathrm{~h}$ after various treatments. $10 \mathrm{ng} / \mathrm{mL}$ TGF- $\beta$ was used as the positive control. (B) The wound-healing percentage $8 \mathrm{~h}$ post-treatment is shown on the $y$ axis, normalized against the initial time $(0 \mathrm{~h})$, for each treatment condition. Bars indicate SD, $n=3,{ }^{*}$ indicates a significant difference $(p<0.05)$ compared to the medium control (Student's $t$-test). CICA: Centella asiatica.

Above reports explain that the solvent may the key factor effect on the proliferation of migrated cell and to confirm the feasibility by using algae extract as resource for wound healing. The potential function of wound healing may be due to the glycosaminoglycan (GAG) extract from algae mediates cellular interaction and growth factor signaling pathways associated with wound recovery process [41,42]. Although not compare multiple solvent extracts on the effect of wound-healing here, however, we clearly demonstrated the feasibility of using hot-water extract of C. microphysa to induce the wound-healing activity of 3T3-L1 fibroblasts. Overall, these results suggest that CME had comparable healing effects.

\subsection{Hydroxyproline Production and In Vitro Permeation Assay}

The process of skin aging is mainly due to the slowing down of the proliferation of keratinocytes in the epidermis and fibroblasts in the dermis, resulting in the reduction of extracellular matrix of the dermis, including collagen, elastin, proteoglycans, glycosaminoglycans. Among these molecules, collagen is considered the most important [43]. Currently, mechanisms underlying the loss of collagen in aging or damaged skin have not been fully delineated. It is known that collagen synthesis is highly regulated by genes. Previous studies have found the plant-derived compounds with anti-oxidant properties can restore fibroblast function through modulation of signaling pathways like MAPKs and NF-кB [3]. 
Hydroxyproline is the compound produced upon digestion of collagen and elastin, and it has been suggested that it may be able to improve aged or damaged skin. In order to evaluate the potential anti-wrinkle properties of $\mathrm{CME}$, an in vitro assay to determine hydroxyproline production was performed. Hydroxyproline concentrations increased in CME-treated hydrolyzed cellular lysates (Figure 8A) relative to the medium control. Cell viability was not affected by treatment condition.

(A)

$$
\begin{aligned}
& \text { - hydroxyproline (24h) } \quad \text { - cell viability }(24 \mathrm{~h}) \\
& \square \text { hydroxyproline (48h) } \quad \text { cell viability (48h) }
\end{aligned}
$$

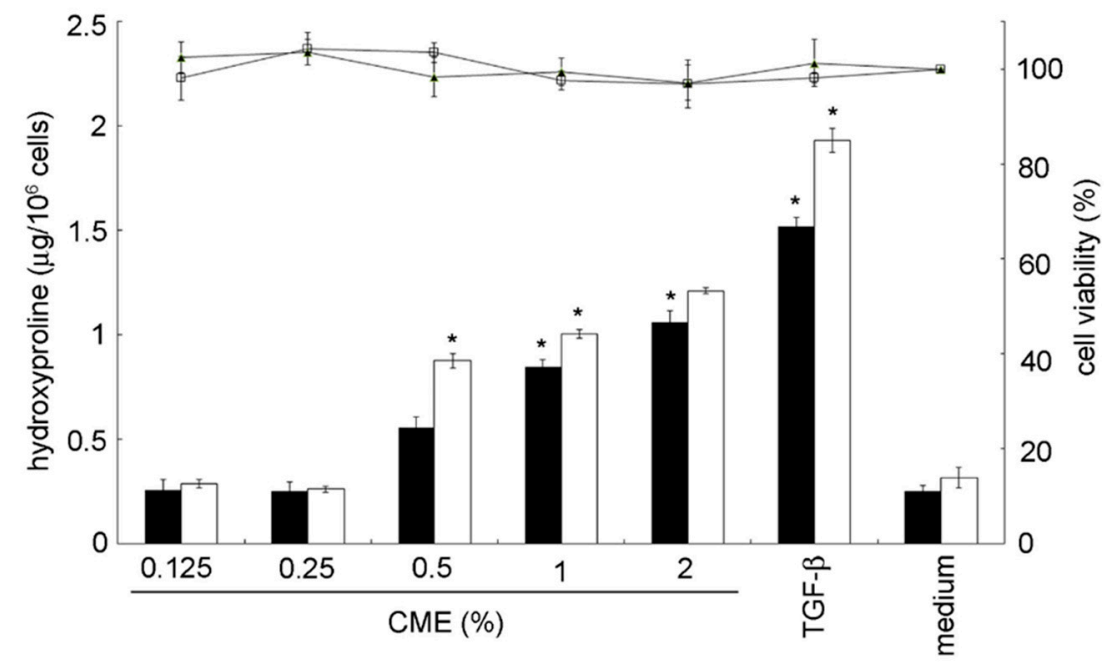

(B)

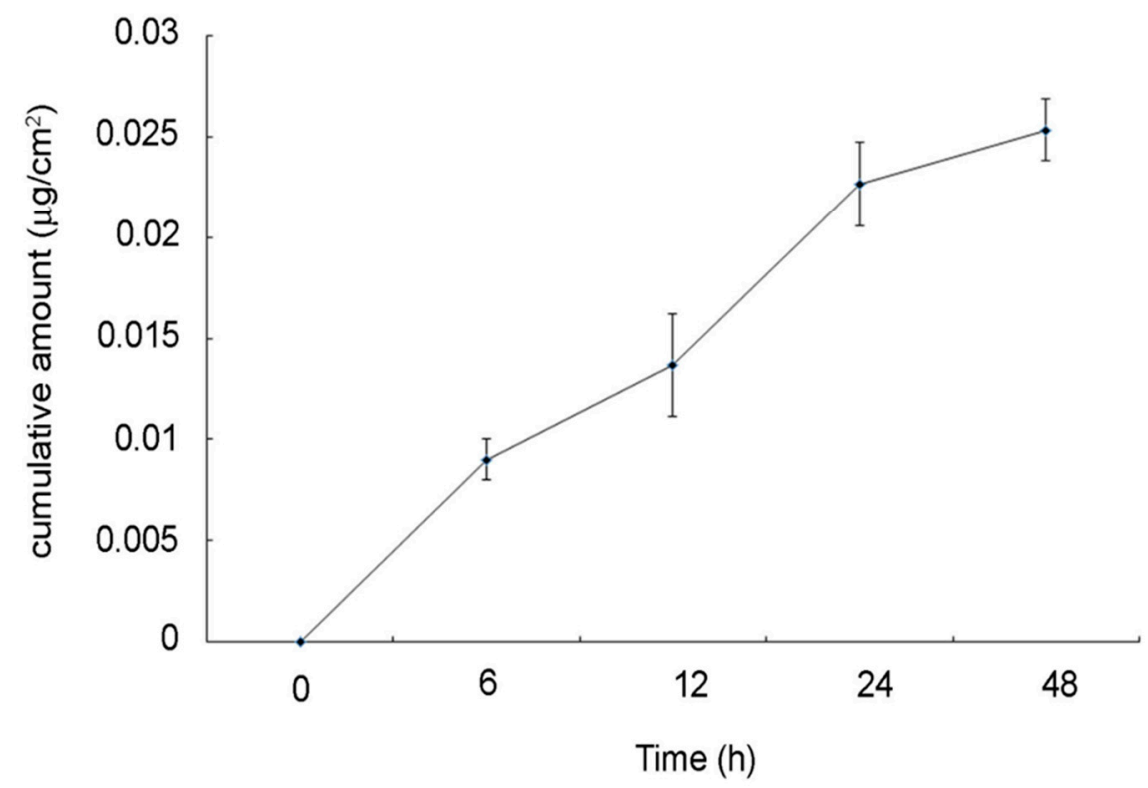

Figure 8. (A) Caulerpa microphysa polysaccharide-rich extract (CME) enhanced hydroxyproline production in a dose-dependent manner. Bars indicate SD, $n=3$ (Student's $t$-test), * indicates a significant difference $(p<0.05)$ compared to the medium control. $10 \mathrm{mg} \mathrm{mL}^{-1}$ TGF- $\beta$ was included as the positive control and for comparison. (B) Cumulative amount of CME that permeated through the Strat-M membrane over time.

To further evaluate the potential of CME for use as a cosmetic raw material, its transdermal-delivery efficacy was measured using a synthetic membrane engineered to 
mimic human skin. This assay aids in predicting diffusion efficiency into human skin for a wide range of materials and compounds. The cumulative total membrane permeation by the CME at various time points is shown in Figure 8B. As can be seen, CME clearly shows potential in terms of cumulative skin permeation.

Few studies have been conducted to evaluate the penetration of raw cosmetics materials, mostly focused on the potential functional proteins on wound response [44]. However, the collagen-producing fibroblasts are located in the skin dermis, thus, effective cosmetics ingredients should be positively correlative with skin penetration. Strat-M ${ }^{\circledR}$ synthetic membrane has similar function on either human cadaver skin or Strat- $\mathrm{M}^{\circledR}$ membrane, which has been regarded as an ideal material for skin penetration investigating.

The factors such as permeability coefficient (Kp), lag time, skin deposition, and molecular size are reported to be relative to the epidermis penetration [45]. Skin tissue plays a crucial role in filtering the entry of substances. As illustrated in a clinical research, the permeability of the epidermis restricted the potential of chemical compounds as drugs, since only compounds with molecules of less than 500 Da can penetrate the skin [46]. According to Figure 3B, fraction B2 of the main polysaccharides of CME, with molecules of $180 \mathrm{Da}$, can pass through the epidermis theoretically. In addition, compared to the lipophilic substances, the hydrophilic substance is more efficient when passing through the stratum corneum barrier. Therefore, we assumed that the water-soluble CME may mainly penetrate the stratum corneum through channels including sweat glands and hair follicles. But, since the two pathways mentioned (sweat glands and hair follicles) only occupy a small ratio of the skin surface area [47], we believe that CME may also penetrate the skin through other channels. In conclusion, CME possessed excellent skin penetration properties, and the critical mechanism worths further exploration.

\subsection{Moisture Absorption and Retention Assay}

It's well known that bio-polysaccharides in cosmetics function as gelling agents, viscosity adjuster, thicker as well as water-holding by means of its swelling capacity [42]. These are due to the polysaccharides can solubilize in water and can also react with skin fibrin to form an extracellular gel matrix, result in moisturizing. Moisturizing is the most important function of skincare products. Effective moisturizing facilitates active moisture absorption and retention by the skin [48]. The moisture absorption and moisture retention properties of CME were therefore assessed and compared with those of several cosmetics on the market in this study.

The moisture absorption results at various time points and humidity levels are shown in Table 4. In terms of water-absorption capacity, CME was better than collagen, similar to hyaluronic acid, and poorer than urea. The moisture-retention capacity over $24 \mathrm{~h}$ is shown in Figure 9, and that of CME was excellent; far better than that of collagen and hyaluronic acid, and similar to that of urea.

The aspect of moisture absorption capacity, when at $81-84 \%$ relative humidity, the water extract of $C$. microphysa showed the optimized water-absorption capacity (78\%) than water extract of Nostoc sphaeroides (29.9-32.5\%) [49], water extract of Enteromorpha prolifera (47.58-61.39\%) [50], and Sargassum horneri (7.4-9.5\%) [51]. On the other hand, the aspect of moisture- retention capacity, the water extract of $C$. microphysa showed the water-absorption capacity at $40 \%$, which was lower than water extract of $N$. sphaeroides (55.6-58.2) [49], E. prolifera (89.50-91.80\%) [50], and S. horneri (49.1-53\%) [51].

Due to the moisture-absorption/retention abilities are effect by complicated biochemistry compounds especially in molecular weight and sulfated content [52]. Thus, further analyzed the molecular weight among the above species, the molecular weight of N. sphaeroides extract was 199-99 kDa [49], S. horneri extract was $179 \mathrm{kDa}$ to $21.42 \mathrm{kDa}$ [51], E. prolifera extract was $147 \mathrm{kDa}$ to $44.8 \mathrm{kDa}$ [50], and C. microphysa extract was $100 \mathrm{kDa}$ to $<50 \mathrm{kDa}$. Although the different molecular weight levels in each species, but seem no correlation with the moisture-absorption/retention abilities. Despite, our result demon- 
strated that CME had high potential and product applicability and could be expected to become a novel multifunctional moisturizer.

Table 4. Moisture-absorption capacity of various sorbents.

\begin{tabular}{cccccc}
\hline \multirow{2}{*}{ Relative Humidity (\%) } & Sample & \multicolumn{4}{c}{ \% Moisture Absorption at Given Time Point (h) } \\
\cline { 3 - 5 } & & $\mathbf{8}$ & $\mathbf{1 2}$ & $\mathbf{2 4}$ & $\mathbf{4 8}$ \\
\hline \multirow{3}{*}{32} & CME & 0 & 0 & 2 & 6 \\
& urea & 0 & 2 & 4 & 10 \\
& hyaluronic acid & 0 & 0 & 2 & 2 \\
& collagen & 0 & 0 & 0 & 0 \\
\hline \multirow{2}{*}{75} & CME & 2 & 17 & 42 & 72 \\
& urea & 0 & 22 & 68 & 87 \\
& hyaluronic acid & 0 & 20 & 39 & 59 \\
& collagen & 0 & 6 & 6 & 7 \\
\hline \multirow{3}{*}{84} & CME & 9 & 18 & 60 & 78 \\
& urea & 20 & 56 & 99 & 119 \\
& hyaluronic acid & 2 & 29 & 78 & 95 \\
& collagen & 2 & 3 & 9 & 19 \\
\hline
\end{tabular}

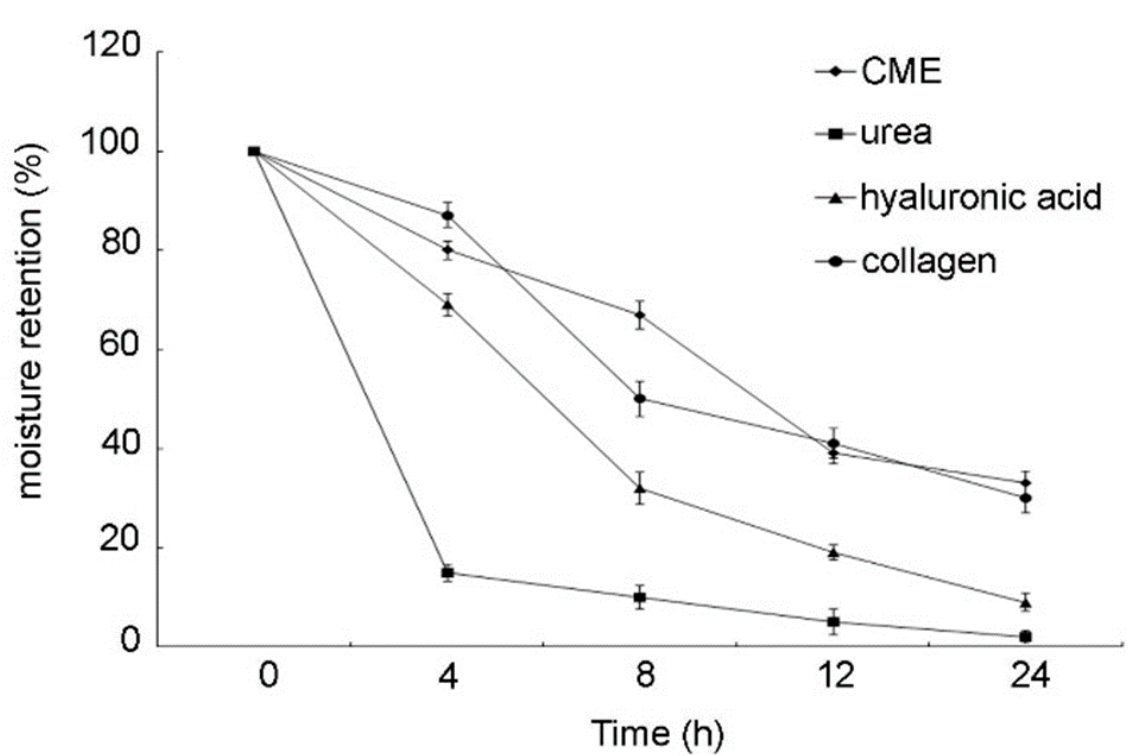

Figure 9. Moisture retention of Caulerpa microphysa polysaccharide-rich extract (CME) samples at $35^{\circ} \mathrm{C}$ and $75 \%$ relative humidity. Bars indicate SD, $n=3$ (One-Way ANOVA and Scheffe's a posteriori test).

\section{Materials and Methods}

\subsection{Cultivation Conditions}

The C. microphysa used in this study was isolated from the intertidal zone in northeastern Taiwan. The algae were washed with $1.5 \%$ povidone-iodine and $2 \mu \mathrm{m}$-filtered UV-irradiated sterilized seawater to remove any adhering debris or epiphytic organisms. They were then cultivated in a $1 \mathrm{t}$ fiberglass tank under a 12:12 $\mathrm{h}$ light:dark regime. The tank was aerated and maintained at an irradiance level of 80-100 $\mu \mathrm{mol}$ photons $\mathrm{m}^{-2} \mathrm{~s}^{-1}$, which was measured using a Lighting Passport spectrometer (ALP-01, Asensetek, New Taipei City, Taiwan). The seawater was refreshed every three days, and $20 \mathrm{~g} \mathrm{t}^{-1}$ ammonium sulfate was added to ensure healthy growth conditions. When the mass of the algae reached $2 \mathrm{~kg}$, they were harvested for the experiments. 


\subsection{Pretreatment and Extraction}

\subsubsection{Extraction of Polysaccharides}

To detect the effect of pretreatment on the polysaccharide content, the biomass of algae was divided into four treatments as follows: (1) fresh algae; (2) milled fresh algae; (3) oven-dried algae; and (4) milled oven-dried algae. Two extraction methods were then investigated: (a) autoclave extraction (SS320, Tominaga, Taipei City, Taiwan), and (b) microwave-ultrasound extraction (EXTRACTOR 200, IDCO, Marseille, France). The fresh and dry treatments were performed using a 1:1 and a 1:0.06 $(v / v)$ mixture, respectively, of the algae with distilled water in a $1 \mathrm{~L}$ serum bottle, the fresh and dry treatments were performed using a 1:1 and a 1:0.06 ( $v / v$, taking moisture loss into consideration) mixture, respectively, of the algae with distilled water in a $1 \mathrm{~L}$ serum bottle. at $40^{\circ} \mathrm{C}$ for $2 \mathrm{~d}$. The fresh and dried algae were milled with a blender (Blendtec, Orem, UT, USA) or a pulverizer at room temperature, respectively. Before extraction, treatments (1) and (2) were stored at $-20{ }^{\circ} \mathrm{C}$ in a freezer, while (3) and (4) were placed in a Moisture-Proof Box (EDRY, Taichung, Taiwan).

At the extraction step, the autoclaved samples were treated at $121{ }^{\circ} \mathrm{C}, 1.5 \mathrm{lbs}$ for $60 \mathrm{~min}$. The microwave-ultrasound samples were treated with sonication at $100 \mathrm{mv}$ and microwaves at $1000 \mathrm{~W}$ and mixed in the microwave-ultrasound extractor for $60 \mathrm{~min}$, and $20 \mathrm{~mL}$ samples were extracted every $10 \mathrm{~min}$. After extraction, all samples were centrifuged at $15,000 \times g$ for $10 \mathrm{~min}$ (CR21G, Hitachi, Tokyo, Japan), after which the supernatant was filtered through a sterile $0.22 \mu \mathrm{m}$ filter membrane (Sartorius, Chöttingen, Germany). The filtered supernatant was freeze-dried into powder (FD10/-80, FIRSTEK, New Taipei, Taiwan), then analyzed for total polysaccharide yield. The optimal extraction conditions were then used for further analysis and in vitro studies.

\subsubsection{Analysis of Total Polysaccharide Content}

To determine the total polysaccharide content, $1 \mathrm{mg}$ of lyophilized powder was dissolved in $20 \mathrm{~mL}$ of ultrapure water and analyzed using the phenol-sulfuric acid method [53].

\subsubsection{Analysis of Sugar Composition}

We assessed the polysaccharide content and sugar composition of the extracted polysaccharide powder using a polysaccharide component assay kit from SugarLight (New Taipei City, Taiwan) following the method of Lin et al. (2010) [54]. A $1 \mathrm{mg}$ sample of purified and dried polysaccharides was added to $1.0 \mathrm{~mL}$ of hydrolysis solution and the resulting mixture was stirred for $2 \mathrm{~h}$ at $80^{\circ} \mathrm{C}$, then dried using a vacuum pump. The resulting powder was mixed well with $2 \mathrm{mg}$ 2,3-naphthalenediamine, $1 \mathrm{mg}$ iodine, and $1 \mathrm{~mL}$ acetic acid, then stirred at room temperature for $1 \mathrm{~h}$ to achieve fluorescent monosaccharide labeling. After drying the solvent, we quantified and qualified the monosaccharidenaphthylimidazole via ${ }^{1} \mathrm{H}$ NMR spectrometry (Bruker AV600, Rheinstetten, Germany) and via HPLC-UV (Hitachi L2130 pump with UV L2420).

\subsubsection{Analysis of Molecular Weight}

The molecular weight of the polysaccharides was determined via high-performance liquid chromatography on a high-resolution gel filtration column (HiPrep 16/60 SephacrylS-200 HR column, Merck, Darmstadt, Germany) with ultrapure water at a flow rate of $0.6 \mathrm{~mL} \mathrm{~min}^{-1}$, detected using a refractive index detector, and visualized using Chromatography Workstation software (EChrom Data System v1.0, Lixing Technology, Hsinchu city, Taiwan).

\subsubsection{Analysis of Polyphenols}

To determine the polyphenol content, $1 \mathrm{mg}$ of lyophilized powder was dissolved in $20 \mathrm{~mL}$ of ultrapure water and analyzed using the Folin-Ciocalteu method [55]. 


\subsubsection{Analysis of Preservation Losses}

To analyze ingredient loss during the freeze-drying process, we evaluated the effects of two different covers on the total polysaccharide and polyphenol content of the extracts. Briefly, $20 \mathrm{~mL}$ of the extraction mixture was added to sterile $50 \mathrm{~mL}$ centrifuge tubes and stored at $-80{ }^{\circ} \mathrm{C}$ for $48 \mathrm{~h}$. Next, aluminum foil or parafilm was used to cover the tube mouth, and the samples were freeze-dried immediately. After $72 \mathrm{~h}$, the samples were taken out and injected with an equal volume of distilled water by weight. The total polysaccharide and polyphenol content were then analyzed and compared to that of the control samples.

\subsection{Analysis of In Vitro Immunostimulatory Activity \\ 3.3.1. Reagents}

We prepared C. microphysa polysaccharide-rich extract (CME) in our laboratory. Quercetin, TGF- $\beta$, and 3-(4,5-dimethylthiazol-2-yl)-2,5-diphenyl-2H-tetrazolium bromide (MTT) were obtained from Sigma (St. Louis, MO, USA). Centella asiatica (CICA) was purchased from Giga Fine Chemical (Taipei, Taiwan). Urea and collagen were purchased from Shunyi Chemical (Taichung, Taiwan), and hyaluronic acid was obtained from Chengyi Chemical (Taipei, Taiwan).

\subsubsection{Analysis of MTT Cytotoxicity}

Cytotoxicity was evaluated via MTT assay according to ISO10993-5. RBL-2H3 cell lines were grown in the required medium and seeded onto a 96-well plate at $5 \times 10^{3}$ cells per well until adherence. Thereafter, the medium was removed, treated with the indicated samples at the indicated concentrations, and further incubated for a range of durations. The MTT was then added and cleaved with mitochondrial reductase to form formazan crystals. The purple formazan was solubilized by adding dimethyl sulfoxide (DMSO), and the optical density (OD) was read at $570 \mathrm{~nm}$, with a reference wavelength of $690 \mathrm{~nm}$, using a microreader (Thermo Scientific, Waltham, MA, USA).

\subsubsection{Analysis of Sensitization and Stimulation for Degranulation}

RBL-2H3 cells were grown in Eagle's minimal essential medium (MEM) containing $4 \mathrm{mM}$ L-glutamine, $1.5 \mathrm{~g} \mathrm{~L}^{-1}$ sodium bicarbonate, $0.1 \mathrm{mM}$ nonessential amino acids, $1 \mathrm{mM}$ sodium pyruvate, and $15 \%$ heat-inactivated fetal bovine serum (FBS). Cells were seeded at $10^{5}$ cells per well in a 24 -well plate. After adherence for $24 \mathrm{~h}$, the cells were sensitized by adding $0.5 \mu \mathrm{g} \mathrm{mL}^{-1}$ anti-DNP IgE (Sigma) for $24 \mathrm{~h}$, washed twice with Siraganian buffer, and incubated with Siraganian buffer for $10 \mathrm{~min}$. They were then treated with CME or CICA and incubated for $2 \mathrm{~h}$. Subsequently, $10 \mu \mathrm{g} \mathrm{mL} \mathrm{m}^{-1}$ of antigen DNP-BSA was added, and the samples were incubated for $20 \mathrm{~min}$ to stimulate degranulation. Quercetin was used as a positive control by followed the method of Mlcek et al., (2016) [56]. The $\beta$-hexosaminidase activity was quantified via a colorimetric reaction using substrate 4-nitrophenyl N-acetyl$\beta$-D-glucosaminide (Sigma) according to the method used by Quah et al., (2020) [57].

\subsubsection{Analysis of Wound Healing}

This experiment was performed by the Industrial Technology Research Institute (Hsinchu, Taiwan). Mouse embryo fibroblast 3T3-L1 (BCRC60159) cells were cultured in Dulbecco's modified Eagle medium (DMEM) containing $4 \mathrm{mM}$ L-glutamine, $1.5 \mathrm{~g} \mathrm{~L}^{-1}$ sodium bicarbonate, $4.5 \mathrm{~g} \mathrm{~L}^{-1}$ glucose, and $10 \%$ calf serum. Cells were seeded onto a SPLScar Block (SPL Life Sciences, Seongnam, Korea) at a density of $2 \times 10^{5}$ cells well $^{-1}$ on a 24-well plate. After adherence for $24 \mathrm{~h}$, the blocks were removed and incubated with medium containing either a test sample or the positive control TGF- $\beta$ for an additional $8 \mathrm{~h}$. The wound area was photographed and the percentage wound-healing rate was calculated as $\left(\mathrm{A}_{0}-\mathrm{A}_{8}\right) / \mathrm{A}_{0}$, where $\mathrm{A}_{0}$ was the wound area at $0 \mathrm{~h}$ and $\mathrm{A}_{8}$ was the wound area at $8 \mathrm{~h}$. Image analysis was performed using ImageJ software v1.8.0_112. 


\subsubsection{Analysis of Hydroxyproline}

Human skin fibroblast CCD966SK cells (BCRC60153) were grown in MEM in Earle's balanced salt solution (BSS) containing $0.1 \mathrm{mM}$ nonessential amino acids, $1.5 \mathrm{~g} \mathrm{~L}^{-1}$ sodium bicarbonate, $1 \mathrm{mM}$ sodium pyruvate, and $10 \%$ FBS. The cells were seeded on a 24 -well plate at $2 \times 10^{5}$ cells well $^{-1}$ overnight to ensure adherence, then incubated with either $\mathrm{CME}$ at various concentrations or the positive control, TGF- $\beta$. Hydroxyproline was measured using a commercially available kit (Biovision, Milpitas, CA, USA) according to the manufacturer's instructions. Absorbance was determined at $560 \mathrm{~nm}$ using an ELISA reader (Thermo Scientific).

\subsubsection{In Vitro Permeation Studies}

In vitro percutaneous absorption was measured using a manual diffusion system (PermeGear, Riegelsville, PA, USA) equipped with Strat-M membrane (Merck), which is a well-established synthetic model for transdermal diffusion testing. The $25 \mathrm{~mm}$ Strat-M membrane was mounted between the donor and receptor compartments and secured tightly with clamps. The available area of the membrane was $0.635 \mathrm{~cm}^{2}$. A $20 \mathrm{mg} \mathrm{mL}^{-1}$ solution of CME was loaded in the donor compartment, and the receptor compartment was filled with phosphate-buffered saline (PBS). The diffusion cells were placed on a magnetic stirring block, and the receptor compartment was maintained at $37^{\circ} \mathrm{C}$ using a circulating water bath. Aliquots of $200 \mu \mathrm{L}$ were withdrawn from the receptor compartment at various time points up to $48 \mathrm{~h}$ and analyzed using a total carbohydrate assay kit (Biovision) to determine the amount of CME that had permeated through the Strat-M membrane.

\subsubsection{Analysis of Moisture Absorption and Retention Capacity}

Both moisture absorption and moisture retention capacity were analyzed according to the method used by Song et al., (2019) [58].

\subsection{Statistical Analysis}

Data were analyzed using Microsoft Excel 2010 and IBM SPSS Statistics 22.0 (IBM, USA). One-way analyses of variance (ANOVAs) were used to test for the significance of differences between pretreatments, water extraction procedures, and moisture retention. Student's $t$-test was used to analyze freeze-drying efficiency, $\beta$-hexosaminidase inhibition, wound healing, hydroxyproline production, and cell viability. Where significant differences were identified by the ANOVAs, we used Scheff'e Test to compare the means across the treatment conditions. All data are presented as the means \pm standard deviation (SD) of three independent experiments, with each experiment performed at least in triplicate. A $p$-value $<0.05$ was considered statistically significant.

\section{Conclusions}

In this study, we described an effective extraction and preservation strategy for CME and performed an analysis of its polysaccharide compositions and molecular weights. We then demonstrated that CME has sufficient safety, antiallergic, and wound-repair properties; enhances hydroxyproline production; and is able to penetrate a Strat-M membrane and accumulate over time. Furthermore, CME possesses excellent moisture-absorption and -retention properties and can aid in the prevention of skin aging in multiple ways. Overall, Caulerpa microphysa has high potential for use in the cosmetics industry.

Author Contributions: M.-C.L.: data curation, writing-original draft. H.-Y.Y.: methodology, visualization. W.-L.S.: conceptualization, writing-review and editing. All authors have read and agreed to the published version of the manuscript.

Funding: This research received no external funding.

Institutional Review Board Statement: Not applicable.

Informed Consent Statement: Not applicable. 


\section{Data Availability Statement: Not applicable.}

Acknowledgments: The authors especially thank the editors and anonymous reviewers for their thoughtful comments.

Conflicts of Interest: The authors declare that they have no known competing financial interests or personal relationships that may have influenced the work reported in this paper.

\section{References}

1. Wells, M.L.; Potin, P.; Craigie, J.S.; Raven, J.A.; Merchant, S.S.; Helliwell, K.E.; Smith, A.G.; Camire, M.E.; Brawley, S.H. Algae as nutritional and functional food sources: Revisiting our understanding. J. Appl. Phycol. 2017, 29, 949-982. [CrossRef]

2. De Jesus Raposo, M.F.; De Morais, A.M.B.; De Morais, R.M.S.C. Marine Polysaccharides from Algae with Potential Biomedical Applications. Mar. Drugs 2015, 13, 2967-3028. [CrossRef]

3. Berthon, J.-Y.; Nachat-Kappes, R.; Bey, M.; Cadoret, J.-P.; Renimel, I.; Filaire, E. Marine algae as attractive source to skin care. Free Radic Res. 2017, 51, 555-567. [CrossRef]

4. Chen, Y.Y.; Xue, Y.T. Optimization of microwave assisted extraction, chemical characterization and antitumor activities of polysaccharides from Porphyra haitanensis. Carbohydr. Polym. 2019, 206, 179-186. [CrossRef] [PubMed]

5. Guidara, M.; Yaich, H.; Amor, I.B.; Fakhfakh, J.; Gargouri, J.; Lassoued, S.; Blecker, C.; Richel, A.; Attia, H.; Garna, H. Effect of extraction procedures on the chemical structure, antitumor and anticoagulant properties of ulvan from Ulva lactuca of Tunisia coast. Carbohydr. Polym. 2021, 253, 117283. [CrossRef]

6. Pandeirada, C.O.; Maricato, É.; Ferreira, S.S.; Correia, V.G.; Pinheiro, B.A.; Evtuguin, D.V.; Palma, A.S.; Correia, A.; Vilanova, M.; Coimbra, M.A.; et al. Structural analysis and potential immunostimulatory activity of Nannochloropsis oculata polysaccharides. Carbohydr. Polym. 2019, 222, 114962. [CrossRef]

7. Ansari, F.A.; Shriwastav, A.; Gupta, S.K.; Rawat, I.; Guldhe, A.; Bux, F. Lipid extracted algae as a source for protein and reduced sugar: A step closer to the biorefinery. Bioresour. Technol. 2015, 179, 559-564. [CrossRef]

8. Fu, C.-C.; Hung, T.-C.; Chen, J.-Y.; Su, C.-H.; Wu, W.-T. Hydrolysis of microalgae cell walls for production of reducing sugar and lipid extraction. Bioresour. Technol. 2010, 101, 8750-8754. [CrossRef] [PubMed]

9. Gao, M.-T.; Shimamura, T.; Ishida, N.; Takahashi, H. Investigation of utilization of the algal biomass residue after oil extraction to lower the total production cost of biodiesel. J. Biosci. Bioeng. 2012, 114, 330-333. [CrossRef] [PubMed]

10. Hung, W.-T.; Chen, Y.-T.; Chen, C.-H.; Lee, Y.C.; Fang, J.-M.; Yang, W.-B. Flow Chemistry System for Carbohydrate Analysis by Rapid Labeling of Saccharides after Glycan Hydrolysis. SLAS Technol. Transl. Life Sci. Innov. 2020, 25, 356-366. [CrossRef] [PubMed]

11. Lee, J.B.; Hayashi, K.; Maeda, M.; Hayashi, T. Antiherpetic activities of sulfated polysaccharides from green algae. Planta Med. 2004, 70, 813-817. [CrossRef]

12. Chen, Y.-T.; Hung, W.-T.; Wang, s.-h.; Fang, J.-M.; Yang, W.-B. Quantitative analysis of sugar ingredients in beverages and food crops by an effective method combining naphthimidazole derivatization and 1H-NMR spectrometry. Funct. Foods Health Dis. 2017, 7, 494. [CrossRef]

13. Park, Y.K.; Rasmussen, H.E.; Ehlers, S.J.; Blobaum, K.R.; Lu, F.; Schlegal, V.L.; Carr, T.P.; Lee, J.Y. Repression of proinflammatory gene expression by lipid extract of Nostoc commune var sphaeroides Kützing, a blue-green alga, via inhibition of nuclear factor-kappaB in RAW 264.7 macrophages. Nutr. Res. 2008, 28, 83-91. [CrossRef] [PubMed]

14. Kimiya, T.; Ohtani, K.; Satoh, S.; Abe, Y.; Ogita, Y.; Kawakita, H.; Hamada, H.; Konishi, Y.; Kubota, S.; Tominaga, A. Inhibitory effects of edible marine algae extracts on degranulation of RBL-2H3 cells and mouse eosinophils. Fish. Sci. 2009, 74, 1157-1165. [CrossRef]

15. Syarina, P.N.; Karthivashan, G.; Abas, F.; Arulselvan, P.; Fakurazi, S. Wound healing potential of Spirulina platensis extracts on human dermal fibroblast cells. Excli J. 2015, 14, 385-393. [CrossRef]

16. Morone, J.; Alfeus, A.; Vasconcelos, V.; Martins, R. Revealing the potential of cyanobacteria in cosmetics and cosmeceuticals-A new bioactive approach. Algal Res. 2019, 41, 101541. [CrossRef]

17. Silva, T.H.; Alves, A.; Ferreira, B.M.; Oliveira, J.M.; Reys, L.L.; Ferreira, R.J.F.; Sousa, R.A.; Silva, S.S.; Mano, J.F.; Reis, R.L. Materials of marine origin: A review on polymers and ceramics of biomedical interest. Int. Mater. Rev. 2012, 57, 276-306. [CrossRef]

18. Shi, C.-H.; Lee, T.-M. Field survey and culture studies of Caulerpa in Taiwan. Ph.D. Dissertation, National Sun Yat-sen University, Kaohsiung City, Taiwan, 2008.

19. Lin, H.-C.; Chou, S.; Chuang, M.-Y.; Liao, T.-Y.; Tsai, W.-S.; Chiu, T.-H. The effects of Caulerpa microphysa enzyme-digested extracts on ACE-inhibitory activity and in vitro anti-tumour properties. Food Chem. 2012, 134, 2235-2241. [CrossRef] [PubMed]

20. Costa, M.S.S.P.; Costa, L.S.; Cordeiro, S.L.; Almeida-Lima, J.; Dantas-Santos, N.; Magalhães, K.D.; Sabry, D.A.; Albuquerque, I.R.L.; Pereira, M.R.; Leite, E.L.; et al. Evaluating the possible anticoagulant and antioxidant effects of sulfated polysaccharides from the tropical green alga Caulerpa cupressoides var. flabellata. J. Appl. Phycol. 2012, 24, 1159-1167. [CrossRef]

21. Barbier, P.; Guise, S.; Huitorel, P.; Amade, P.; Pesando, D.; Briand, C.; Peyrot, V. Caulerpenyne from Caulerpa taxifolia has an antiproliferative activity on tumor cell line SK-N-SH and modifies the microtubule network. Life Sci. 2001, 70, 415-429. [CrossRef] 
22. Cavas, L.; Basbinar, Y.; Yurdakoc, K.; Olgun, N. Antiproliferative and newly attributed apoptotic activities from an invasive marine alga: Caulerpa racemosa var. cylindracea. J. Exp. Mar. Biol. Ecol. 2006, 339, 111-119. [CrossRef]

23. Guldhe, A.; Singh, B.; Rawat, I.; Ramluckan, K.; Bux, F. Efficacy of drying and cell disruption techniques on lipid recovery from microalgae for biodiesel production. Fuel 2014, 128, 46-52. [CrossRef]

24. Prabakaran, P.; Ravindran, A.D. A comparative study on effective cell disruption methods for lipid extraction from microalgae. Lett. Appl. Microbiol. 2011, 53, 150-154. [CrossRef] [PubMed]

25. Xu, S.-Y.; Huang, X.; Cheong, K.-L. Recent Advances in Marine Algae Polysaccharides: Isolation, Structure, and Activities. Mar. Drugs 2017, 15, 388. [CrossRef]

26. Sasaki, M.; Takagi, A.; Sasaki, D.; Nakamura, A.; Asayama, M. Characteristics and function of an extracellular polysaccharide from a green alga Parachlorella. Carbohydr. Polym. 2021, 254, 117252. [CrossRef]

27. He, X.; Yamauchi, A.; Nakano, T.; Yamaguchi, T.; Ochiai, Y. The composition and anti-inflammatory effect of polysaccharides from the red alga Chondrus verrucosus. Fish. Sci. 2019, 85, 859-865. [CrossRef]

28. Guo, M.; Li, Z.; Huang, Y.; Shi, M. Polysaccharides from Nostoc commune Vaucher activate macrophages via NF- $\mathrm{B}$ and AKT/JNK1/2 pathways to suppress colorectal cancer growth in vivo. Food Funct. 2019, 10, 4269-4279. [CrossRef] [PubMed]

29. Ji, H.; Shao, H.; Zhang, C.; Hong, P.; Xiong, H. Separation of the polysaccharides in Caulerpa racemosa and their chemical composition and antitumor activity. J. Appl. Polym. Sci. 2008, 110, 1435-1440. [CrossRef]

30. Chattopadhyay, K.; Adhikari, U.; Lerouge, P.; Ray, B. Polysaccharides from Caulerpa racemosa: Purification and structural features. Carbohydr. Polym. 2007, 68, 407-415. [CrossRef]

31. Ciancia, M.; Fernández, P.V.; Leliaert, F. Diversity of Sulfated Polysaccharides From Cell Walls of Coenocytic Green Algae and Their Structural Relationships in View of Green Algal Evolution. Front. Plant Sci. 2020, 11, 554585. [CrossRef]

32. Meltzer, E.O.; Grant, J.A. Impact of cetirizine on the burden of allergic rhinitis. Ann. Allergy Asthma Immunol. 1999, 83, 455-463. [CrossRef]

33. Sicherer, S.H.; Muñoz-Furlong, A.; Sampson, H.A. Prevalence of peanut and tree nut allergy in the United States determined by means of a random digit dial telephone survey: A 5-year follow-up study. J. Allergy Clin. Immunol. 2003, 112, 1203-1207. [CrossRef]

34. Ishizaka, T.J.J.o.A.; Immunology, C. Analysis of triggering events in mast cells for immunoglobulin E-mediated histamine release. J. Allergy Clin. Immunol. 1981, 67, 90-96. [CrossRef]

35. Metzger, H.; Alcaraz, G.; Hohman, R.; Kinet, J.P.; Pribluda, V.; Quarto, R. The receptor with high affinity for immunoglobulin E. Annu. Rev. Immunol. 1986, 4, 419-470. [CrossRef] [PubMed]

36. Zhang, N.-n.; Park, D.K.; Park, H.-J. The inhibitory activity of atractylenolide III, a sesquiterpenoid, on IgE-mediated mast cell activation and passive cutaneous anaphylaxis (PCA). J. Ethnopharmacol. 2013, 145, 278-285. [CrossRef]

37. Maruyama, H.; Tamauchi, H.; Hashimoto, M.; Nakano, T. Suppression of Th2 immune responses by mekabu fucoidan from Undaria pinnatifida sporophylls. Int. Arch. Allergy Immunol. 2005, 137, 289-294. [CrossRef] [PubMed]

38. Kurahashi, T.; Fujii, J. Roles of Antioxidative Enzymes in Wound Healing. J. Dev. Biol. 2015, 3, 57-70. [CrossRef]

39. Kubota, K.; Okazaki, J.; Louie, O.; Kent, K.C.; Liu, B. TGF-beta stimulates collagen (I) in vascular smooth muscle cells via a short element in the proximal collagen promoter. J. Surg. Res. 2003, 109, 43-50. [CrossRef]

40. Muhammad, A.A.; Pauzi, N.A.S.; Arulselvan, P.; Abas, F.; Fakurazi, S. In Vitro Wound Healing Potential and Identification of Bioactive Compounds from Moringa oleifera Lam. BioMed Res. Int. 2013, 2013, 974580. [CrossRef]

41. Lee, K.Y.; Mooney, D.J. Alginate: Properties and biomedical applications. Prog. Polym. Sci. 2012, 37, 106-126. [CrossRef]

42. Melrose, J. Glycosaminoglycans in Wound Healing. Bone Tissue Regen. Insights 2016, 7, BTRI.S38670. [CrossRef]

43. Mora Huertas, A.C.; Schmelzer, C.E.H.; Hoehenwarter, W.; Heyroth, F.; Heinz, A. Molecular-level insights into aging processes of skin elastin. Biochimie 2016, 128-129, 163-173. [CrossRef] [PubMed]

44. Ender, F.; Hallmann, A.; Amon, P.; Sumper, M. Response to the Sexual Pheromone and Wounding in the Green Alga Volvox: Induction of an Extracellular Glycoprotein Consisting Almost Exclusively of Hydroxyproline. J. Biol. Chem. 1999, $274,35023-35028$. [CrossRef]

45. Holmgaard, R.; Nielsen, J. Dermal Absorption of Pesticides: Evaluation of Variability and Prevention; Danish Environmental Protection Agency: Haraldsgade, Denmark, 2008.

46. Bos, J.D.; Meinardi, M.M. The 500 Dalton rule for the skin penetration of chemical compounds and drugs. Exp. Dermatol. 2000, 9, 165-169. [CrossRef]

47. Schaefer, H.; Lademann, J. The role of follicular penetration. A differential view. Skin Pharmacol. Appl. Skin Physiol. 2001, 14 (Suppl. 1), 23-27. [CrossRef]

48. Wang, L.; Jayawardena, T.U.; Yang, H.-W.; Lee, H.-G.; Jeon, Y.-J. The Potential of Sulfated Polysaccharides Isolated from the Brown Seaweed Ecklonia maxima in Cosmetics: Antioxidant, Anti-melanogenesis, and Photoprotective Activities. Antioxidants 2020, 9, 724. [CrossRef] [PubMed]

49. Li, H.; Su, L.; Chen, S.; Zhao, L.; Wang, H.; Ding, F.; Chen, H.; Shi, R.; Wang, Y.; Huang, Z. Physicochemical Characterization and Functional Analysis of the Polysaccharide from the Edible Microalga Nostoc sphaeroides. Molecules 2018, 23, 508. [CrossRef] [PubMed]

50. Li, J.; Chi, Z.; Yu, L.; Jiang, F.; Liu, C. Sulfated modification, characterization, and antioxidant and moisture absorption/retention activities of a soluble neutral polysaccharide from Enteromorpha prolifera. Int. J. Biol. Macromol. 2017, 105, 1544-1553. [CrossRef] 
51. Shao, P.; Chen, X.; Sun, P. Improvement of antioxidant and moisture-preserving activities of Sargassum horneri polysaccharide enzymatic hydrolyzates. Int. J. Biol. Macromol. 2015, 74, 420-427. [CrossRef]

52. Wang, J.; Jin, W.; Hou, Y.; Niu, X.; Zhang, H.; Zhang, Q. Chemical composition and moisture-absorption/retention ability of polysaccharides extracted from five algae. Int. J. Biol. Macromol. 2013, 57, 26-29. [CrossRef]

53. DuBois, M.; Gilles, K.A.; Hamilton, J.K.; Rebers, P.A.; Smith, F. Colorimetric Method for Determination of Sugars and Related Substances. Anal. Chem. 1956, 28, 350-356. [CrossRef]

54. Lin, C.; Hung, W.-T.; Kuo, C.-Y.; Liao, K.-S.; Liu, Y.-C.; Yang, W.-B. I2-Catalyzed Oxidative Condensation of Aldoses with Diamines: Synthesis of Aldo-Naphthimidazoles for Carbohydrate Analysis. Molecules 2010, 15, 1340-1353. [CrossRef] [PubMed]

55. Kuda, T.; Tsunekawa, M.; Goto, H.; Araki, Y. Antioxidant properties of four edible algae harvested in the Noto Peninsula. J. Food Compos. Anal. 2005, 18, 625-633. [CrossRef]

56. Mlcek, J.; Jurikova, T.; Skrovankova, S.; Sochor, J. Quercetin and Its Anti-Allergic Immune Response. Molecules 2016, $21,623$. [CrossRef] [PubMed]

57. Quah, Y.; Lee, S.-J.; Lee, E.-B.; Birhanu, B.T.; Ali, M.S.; Abbas, M.A.; Boby, N.; Im, Z.-E.; Park, S.-C. Cornus officinalis Ethanolic Extract with Potential Anti-Allergic, Anti-Inflammatory, and Antioxidant Activities. Nutrients. 2020, 12, 3317. [CrossRef] [PubMed]

58. Song, L.; Xie, W.; Zhao, Y.; Lv, X.; Yang, H.; Zeng, Q.; Zheng, Z.; Yang, X. Synthesis, Antimicrobial, Moisture Absorption and Retention Activities of Kojic Acid-Grafted Konjac Glucomannan Oligosaccharides. Polymers 2019, 11, 1979. [CrossRef] 